\title{
Have Global Value Chains Contributed to Global Imbalances?
}

Haltmaier, Jane

Haltmaier, Jane (2015). Have Global Value Chains Contributed

to Global Imbalances?. International Finance Discussion

Papers 1154.

http://dx.doi.org/10.17016/IFDP.2015.1154

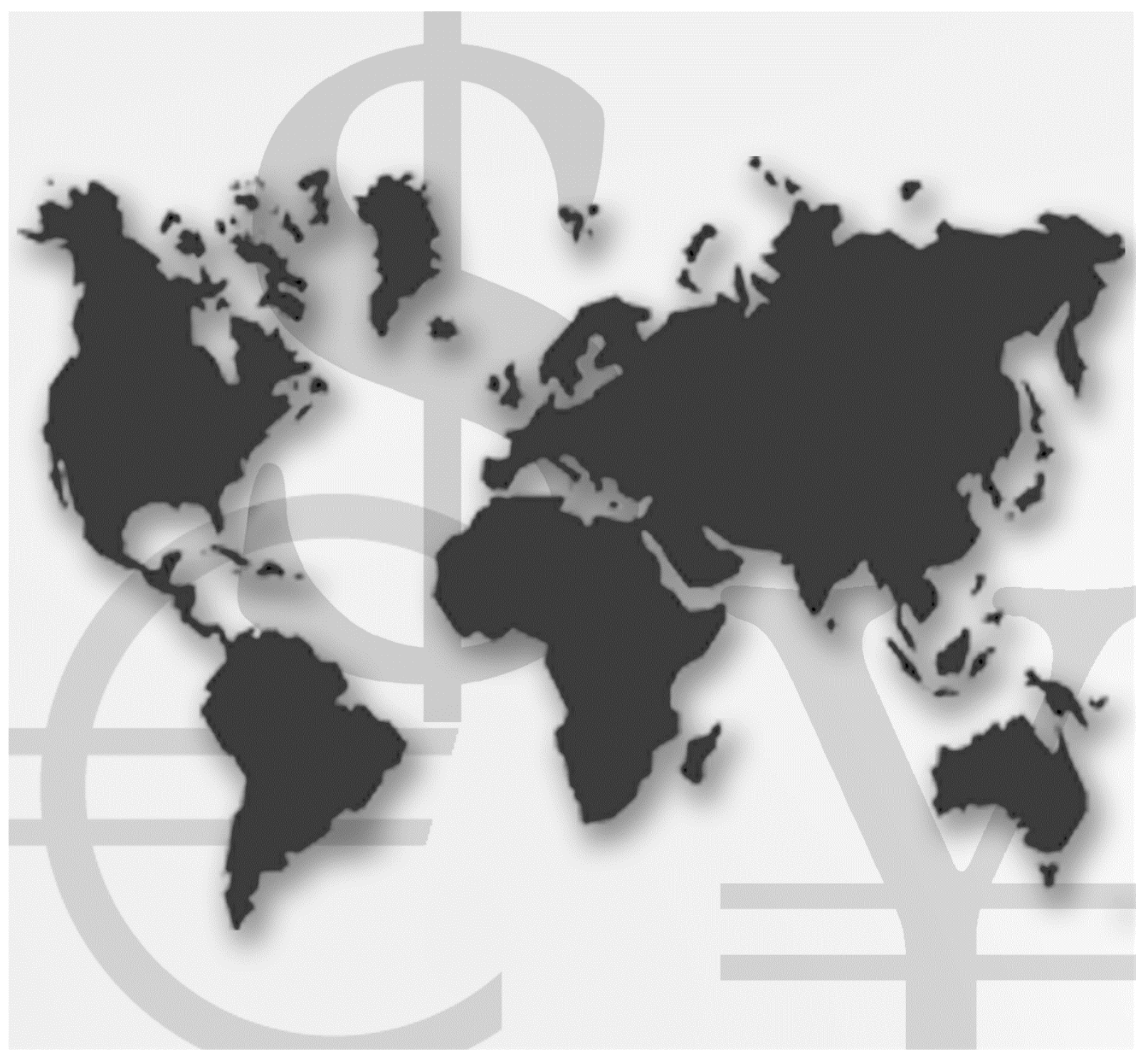

\section{International Finance Discussion Papers}

Board of Governors of the Federal Reserve System

Number 1154

December 2015 


\title{
Board of Governors of the Federal Reserve System
}

International Finance Discussion Papers

Number 1154

December 2015

\section{Have Global Value Chains Contributed to Global Imbalances?}

\author{
Jane Haltmaier
}

Note: International Finance Discussion Papers are preliminary materials circulated to stimulate discussion and critical comment. References to International Finance Discussion Papers (other than an acknowledgement that the writer has had access to unpublished material) should be cleared with the author. Recent IFDPs are available on the web at www.federal reserve.gov/pubs/ifdp. This paper can be downloaded without charge from Social Science Research Network electronic library at www.ssrn.com. 


\title{
Have Global Value Chains Contributed to Global Imbalances?
}

\author{
Jane Haltmaier*
}

\begin{abstract}
Global value chains (GVCs) have grown rapidly over the past several decades. Over the same period, the aggregate value of current account imbalances has risen substantially. This paper looks at whether these developments are related. While there is a sizable literature that has documented the rise of global production networks, there have been few attempts to assess the potential effect on global imbalances. The paper uses measures of GVCs developed in the literature in panel regressions to assess the effect on global imbalances over the period 19952011. It is argued that these variables should be entered as a product rather than individually and that they should be lagged, not contemporaneous with the change in current account balances. The results suggest that GVC position weighted by participation and trade share is negatively related to a country's current account balance, i.e., moving upstream in the production process is negative for a country's current account. However, the effects on global imbalances over the period studied appear to be small.
\end{abstract}

Keywords: global value chains, current account balances

JEL classifications: F1, F4

*Senior Advisor in the Division of International Finance, Board of Governors of the Federal Reserve System, Washington D.C. 20551, U.S.A. Email: Jane.T.Haltmaier@frb.gov, Jane.Haltmaier@gmail.com. Telephone: (202)-452-2374; fax (202)-263-4850.

The views presented in this paper are solely the responsibility of the author and should not be interpreted as reflecting the views of the Board of Governors of the Federal Reserve System or of any other person associated with the Federal Reserve System. 


\section{Have Global Value Chains Contributed to Global Imbalances?}

\section{Introduction}

One of the more noteworthy economic developments of the late $20^{\text {th }}$ and early $21^{\text {st }}$ centuries has been a rapid increase in global trade. Increased openness to trade is generally considered to be positive for economic growth for both individual economies and for the global economy as a whole, as it allows countries to specialize in producing goods and services in which they have a comparative advantage and it may also foster the transfer of technology across borders.

As shown in figure 1, the rise in trade does appear to have been associated with some increase in global growth before the financial crisis in 2008-2009. However, there is some question as to how sustainable and balanced the gains have been. As shown in figure 2, the rise in global trade relative to GDP also was accompanied by a sharp increase in the absolute value of global current account balances as a percentage of GDP. Global imbalances narrowed considerably during the financial crisis and have remained at a lower level, while the ratio of trade to GDP has regained much of its earlier decline but has not resumed its upward trend. This raises the questions of whether the higher global growth in the pre-crisis period was connected to the rapid increase in trade as well as to the rise in global imbalances, whether these imbalances will re-emerge if trade again begins to grow more rapidly than GDP, and whether it will be possible for GDP growth to return to pre-crisis rates if trade growth and imbalances do not. 
Figure 1

6

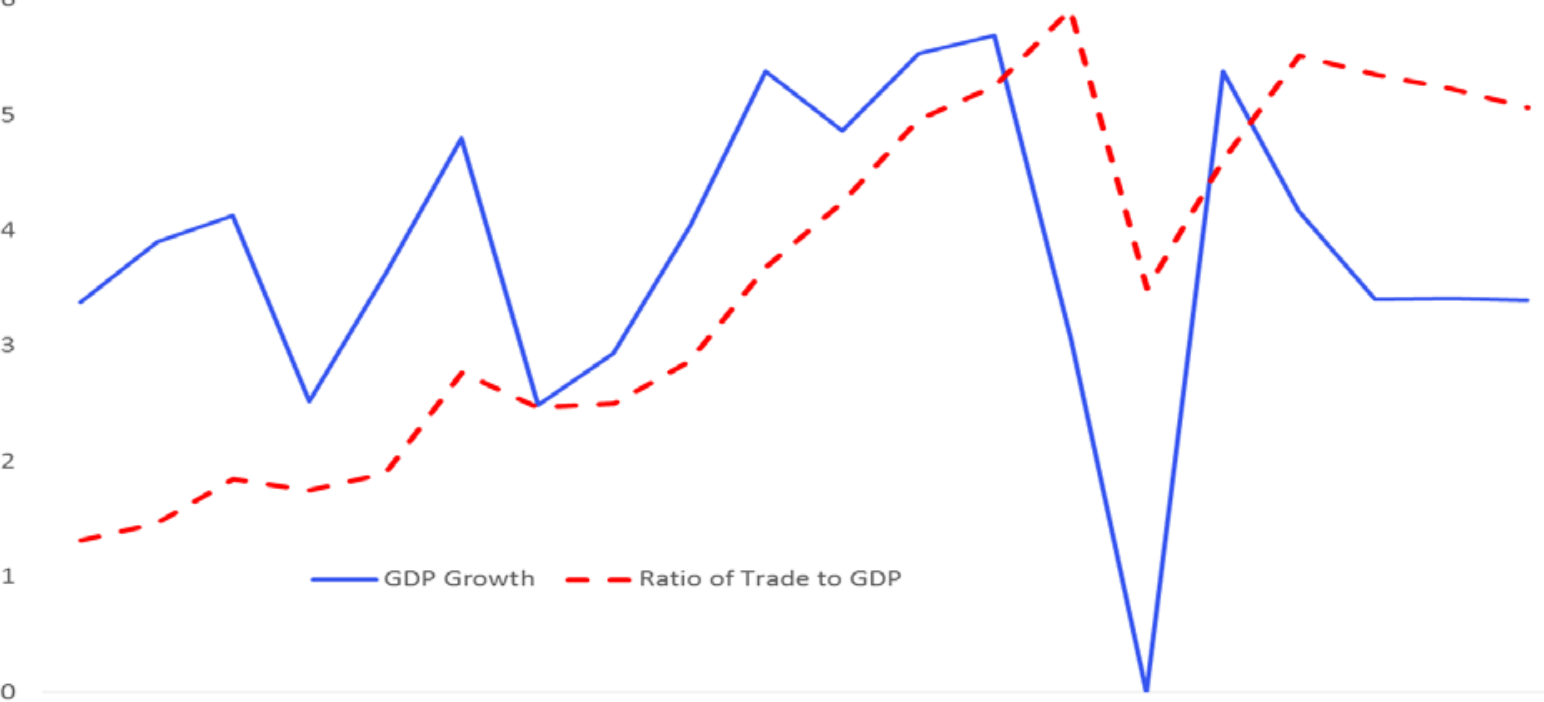

26

24

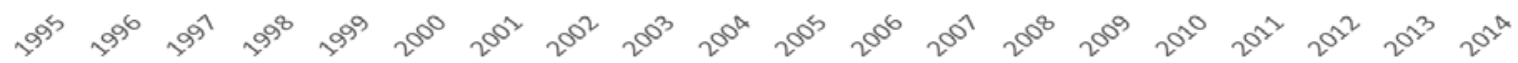

Figure 2

5 Ratio of Trade to GDP and Absolute Value of Current Account Balances

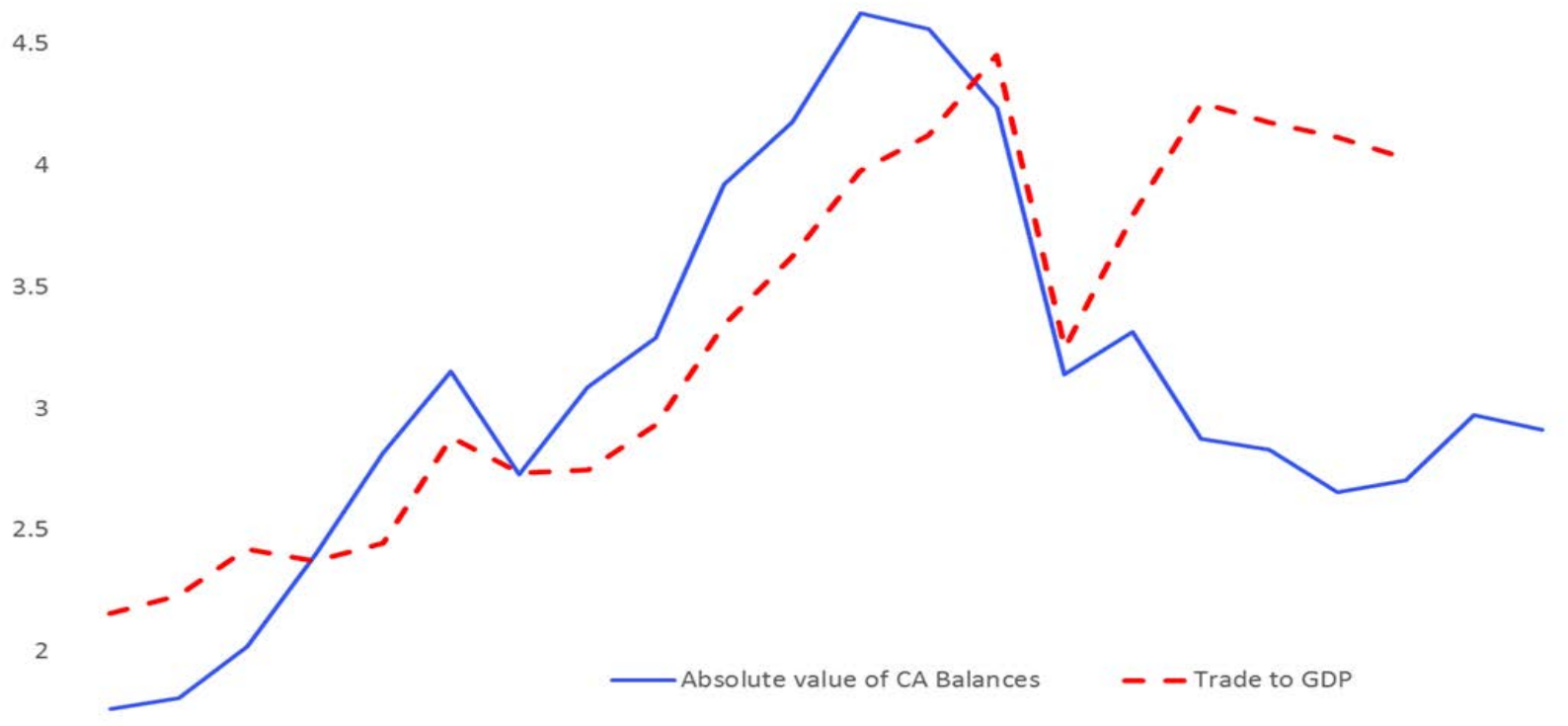


This paper does not attempt to answer all of these questions. It looks at one piece of the puzzle, namely whether the association between the increase in global trade and the rise in current account balances in the pre-crisis period were both related to the proliferation of global value chains (GVCs), otherwise known as production fragmentation, in which the production process is dispersed across countries. In such chains a source country produces intermediate goods that are then used in other countries to assemble the final product. There can be many links in such chains, so that the components of a final product may cross borders several times, sometimes round-tripping between countries, before the final product is assembled. Reductions in costs for transportation and communication, an acceleration in technical progress that has allowed production to be standardized to that point the it can be geographically dispersed, and trade liberalization have all been cited as explanations for the rapid growth in GVCs.

Is there any reason why we might expect such production chains to result in an increase in global imbalances? There are two obvious possibilities: one is that participation in global value chains causes a country's current account balance to increase or decrease, which would need to be matched by an offsetting change in the current account balances of non-participating countries. However, this is more likely to be true if only a subset of countries participate in such chains, since otherwise changes in participating countries would need to be offsetting. Another possibility is that the effect on current account balances differs depending on a country's position in the global value chain. Some countries, usually the more advanced, are more "upstream" in the chain, producing technologically advanced parts and components and sending them downstream to less advanced countries for the less skill-intensive assembly process.

Although there has been a great deal of work on the characterization of global value chains, there has been little analysis of the link between value chains and current account 
balances. One of the first is a paper by Georgiadis, Grab, and Trottner (GTT, 2014) that suggests that participation in global value chains should have a positive effect on a country's current account balance because the process involves adding value to imports and then exporting them, which would mathematically increase the trade balance. However, this assumes that the country is relatively downstream in the production chain. Countries whose primary role is to export intermediates for further processing in other countries would not see such an effect on their current account balance.

Some related work has found that trade involving production chains in a downstream country may be less responsive to changes in exchange rates because currency appreciation will reduce the cost of imports even as it is making that country's exports more expensive, as discussed in Riad et. al. (2012). They find that adjustment to a change in exchange rates takes place mainly outside of the supply chain. Obviously, the larger the supply chain as a percent of trade, the slower the adjustment process will be. Although this phenomenon would not necessarily create a current account imbalance, it could make adjustment more difficult if one should emerge for other reasons.

The purpose of this paper is to assess whether there is any empirical evidence that the rapid growth of global supply chains in the past couple of decades has contributed to the simultaneous increase in global imbalances. Since both position in GVCs and current account balances are effectively zero-sum (if some countries are upstream others must be downstream and if some countries have current account surpluses others must have deficits), association between position and current account balance would suggest that GVCs could contribute to global imbalances, ceteris paribus. 
The first step is to calculate measures of GVCs, a process described in the following section. Section III presents some data showing the evolution of value chains and current account balances since 1995, and section IV describes the results of some panel regressions that attempt to assess the relationships between value chains and the current account. The primary finding is that downstreamness in GVCs in the aggregate does appear to contribute positively to a country’s current account balances while upstreamness does the opposite. However, the magnitude of the effect relative to the growth of global imbalances over the period studied appears to be small. Section V concludes.

\section{Measuring Global Value Chains: A Brief History}

As global value chains have evolved, so have the methods used to characterize them. Initial work on characterization of global value chains, or international fragmentation of production, used the imported input shares of gross output, total inputs, or exports as indicators of the extent of a country's involvement in such chains (see, for instance, Feenstra and Hanson (1996)). ${ }^{1}$ However, Hummels, Ishii, and Yi (2001, hereafter referred to as HIY) and Chen et. al. (2005) argue convincingly that such measures do not accurately characterize global value chains because they do not assess the extent to which the imported intermediates are used in a country's exports as opposed to being used in domestic production. They introduced the concept of “vertical specialization,” which requires three characteristics: (1) goods are produced in stages; (2) two or more countries provide value-added in the production sequence; and (3) at least one country uses imported inputs in its stage of the production process and exports some of the resulting product to either a third country or back to the country of origin. They note that it is the third factor that distinguishes a value chain from simple outsourcing.

\footnotetext{
${ }^{1}$ Amador and Cabral (2014) provide an excellent summary of the evolution of this literature.
} 
HIY developed two measures of vertical specialization for an individual country, one from the import perspective and the other from the export perspective. The first, labelled VS, is the imported intermediate input content of exports and is measured for each country and each product as the amount of imported intermediate input multiplied by the ratio of exports to gross output for that product. The total for a country is calculated by summing across products. This statistic is an approximation to the actual amount of intermediates used for export as it assumes that the ratio of intermediates to output is the same for output that is sold domestically and output that is exported. Aggregate VS for a country is usually expressed as a ratio to total exports. One minus this ratio measures the percentage of exports that consist of domestic value added.

HIY's second measure of vertical specialization (VS1) is from the perspective of exports, and counts the portion of exports that are used by another country in the production of its export goods. It is calculated for each country as the sum over all products and destinations of its exports of intermediates multiplied by the ratio of exports to gross output for that industry in the destination country. Again, this is an approximation that assumes that the usage of each intermediate input is proportionately the same for exports as for products sold domestically.

If the entire world is included in the sample, the aggregates across countries of the two measures should be equal in nominal terms, as the first measures all of the foreign value added embedded in imports and the second measures all of the foreign value added in exports.

More recent work by Johnson and Noguera (2012) and Koopman et. al. (2010) (referred to as KPWW) generalize HIY's vertical specialization measures to cases where production chains are more complicated. In particular, KPWW demonstrate that the HIY measures of vertical specialization do not accurately decompose exports into their foreign and domestic value-added components when the production chain spans several countries, i.e., when one 
country imports intermediate inputs, adds value, and then exports semi-finished goods to another country that produces the final goods. In these cases it is not accurate to assume that imports from a source country embody only domestic value-added from that country, as they may also include value-added from third countries. These more complicated production chains may include the increasingly important phenomenon of round-tripping, in which intermediate goods may cross the same borders several times, with some of a country's intermediate goods imports embodying some of its own value-added.

The development of global input-output tables in recent years has made it much easier to calculate KPWW's broader measures of vertical specialization for a range of countries. This paper uses the World Input-Output tables from the WIOD database ${ }^{2}$, which covers the years from 1995 to 2011. The tables include 40 separate countries and a rest-of-world aggregate and 35 industries. $^{3}$

The information in the input-output tables can be expressed in matrix form as:

(1) $Y=A Y+F$

With c countries and $\mathrm{n}$ industries, $\mathrm{Y}$ is an nc $\mathrm{x} 1$ vector of gross output for all countries and industries, $\mathrm{A}$ is an nc $\mathrm{x}$ nc matrix of input-output coefficients, and $\mathrm{F}$ is an nc $\mathrm{x} 1$ vector of final demand for all countries and industries.

The system can be rewritten as:

(2) $Y=(I-A)^{-1} F=B F$

\footnotetext{
${ }^{2}$ Dietzenbacher et. al. (2013), Timmer et. al. (2015).

3 Thirty-four industries were included in the analysis because the thirty-fifth, private households, contained too many zero entries to allow the matrix to be inverted.
} 
where B is the nc $\mathrm{x}$ nc Leontief matrix that gives the amount of gross output in each country that is required for a one-unit increase in output for final demand in another country.

Using KPWW's notation, the amount of foreign value-added from a source country that is embedded in exports of the destination country is calculated by taking the $\mathrm{n} x \mathrm{n}$ section of the Leontief matrix that links those two countries and pre-multiplying it by a $1 \mathrm{x} n$ vector of the share of value added in gross output for each industry in the source country and post-multiplying it by an $\mathrm{n} x 1$ vector containing the destination country's exports by industry:

(3) $\mathrm{FV}_{\mathrm{rs}}=\mathrm{V}_{\mathrm{s}} \mathrm{B}_{\mathrm{sr}} \mathrm{E}_{\mathrm{r}^{*}}$

where $\mathrm{FV}_{\mathrm{rs}}$ is a scalar measuring foreign value-added from country $s$ to exports in country $r, \mathrm{~V}_{\mathrm{s}}$ is the value-added vector for country $s, \mathrm{~B}_{\mathrm{sr}}$ is the $\mathrm{n} \mathrm{x}$ portion of the global Leontief matrix that links countries $r$ and $s$, and $\mathrm{E}_{\mathrm{r}^{*}}$ is the vector of country $r$ 's exports. Total foreign value-added in the exports of a country is calculated by summing across the contributions for all of the source countries,

(4) $F V_{r}=\Sigma_{s \neq r} V_{s} B_{r s} E_{r^{*}}$

KPWW's analog to HIY's measure of vertical specialization from the export perspective is defined as a country's value-added embodied as intermediate inputs in other countries' gross exports. It is calculated as:

(5) $I V_{r}=\Sigma_{s \neq r} V_{r} B_{s r} E_{s}{ }^{*}$

This measure is thus the mirror image of the specialization measure from the import side, as it uses the value-added vector for the producing country, the matrix linking it to the 
destination country, and the destination country's export vector. Both measures are generally expressed as percentages of total exports. As with the HIY measure of foreign value-added, 1-FV $\mathrm{F}_{\mathrm{r}}$ measures the domestic value added embedded in exports. Also like the HIY measures, the aggregates of the two measures across all countries are equal.

Increases in either or both of these measures are thus symptomatic of greater involvement in value chains. KPWW define a global value chain (GVC) participation index for each country and sector as:

(6) $\mathrm{GVC}$ Participation ${ }_{\text {ir }}=\left(\mathrm{IV}_{\text {ir }}+\mathrm{FV}_{\mathrm{ir}}\right) / \mathrm{E}_{\mathrm{ir}}$

KPWW also define a position index that codifies the relative upstreamness of a country in a particular industry. They propose measuring upstreamness as the log ratio of a country's supply of intermediates used in other countries' exports to the use of imported intermediates in its own production:

(7) $\mathrm{GVC}_{\text {Position }}=\ln \left(1+\mathrm{IV}\right.$ ir $\left./ \mathrm{E}_{\text {ir }}\right)-\ln \left(1+\mathrm{FV}_{\text {ir }} / \mathrm{E}_{\mathrm{ir}}\right)$

Countries with a larger position index are relatively upstream (they contribute more value added to other countries exports than other countries contribute to theirs).

The analysis that follows uses each country's aggregate measure of both participation and position. It should be noted that the measures calculated here rely on the proportionality assumption—-that is, they assume that the same input-output table applies for processing as for non-processing trade. This assumption clearly does not hold for countries such as China and Mexico, which KPWW illustrate in their paper by adjusting the data for those countries for 2004. However, calculating adjusted measures for all of the years used in this study would be very 
difficult, and it should probably be done for more countries in any case. The analysis here is done in first difference form, so while not adjusting for processing trade likely introduces some error, it should be less important in first differences than in levels. In any case, future work will attempt to address this deficiency.

\section{Developments Since 1995}

Figure 3 shows the measure of GVC participation aggregated over all countries. It displays the same upward trend as the ratio of trade to GDP shown earlier and appears to show a similar trend to that of global current account imbalances, at least through 2010.

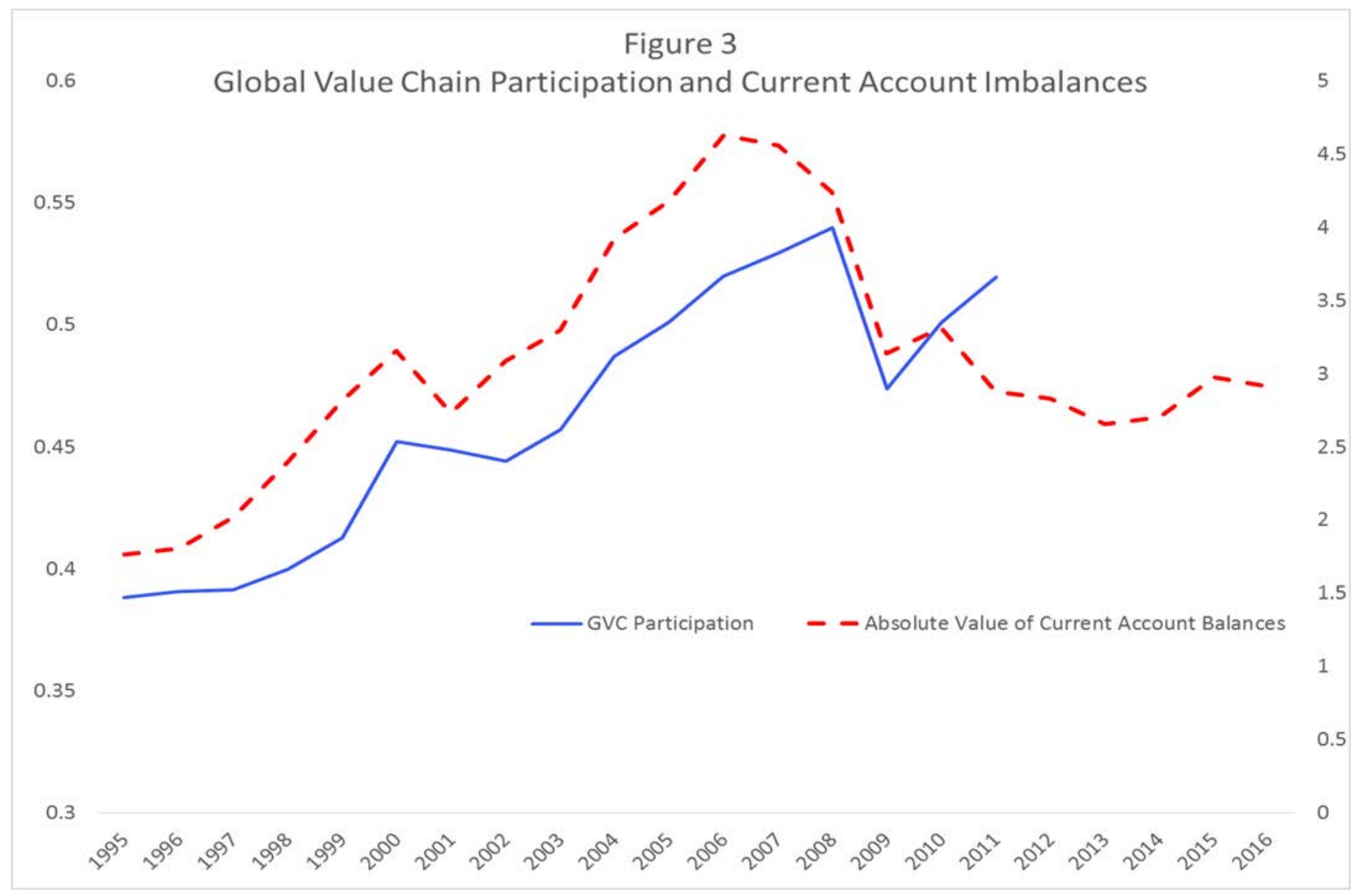


Figure 4 shows measures of participation for selected advanced economies and Figure 5 shows them for emerging market economies. The increase in GVC participation is clearly quite widespread across both groups. Among advanced economies, participation is higher for the European economies than for Japan, the United States, and Canada, but it has risen the most rapidly for Japan. Participation rates are generally higher for emerging market economies, particularly in emerging Europe and emerging Asia (recall that the measures for China and Mexico, and possibly other countries, are understated). Brazil, however, appears to be much less engaged in GVCs.

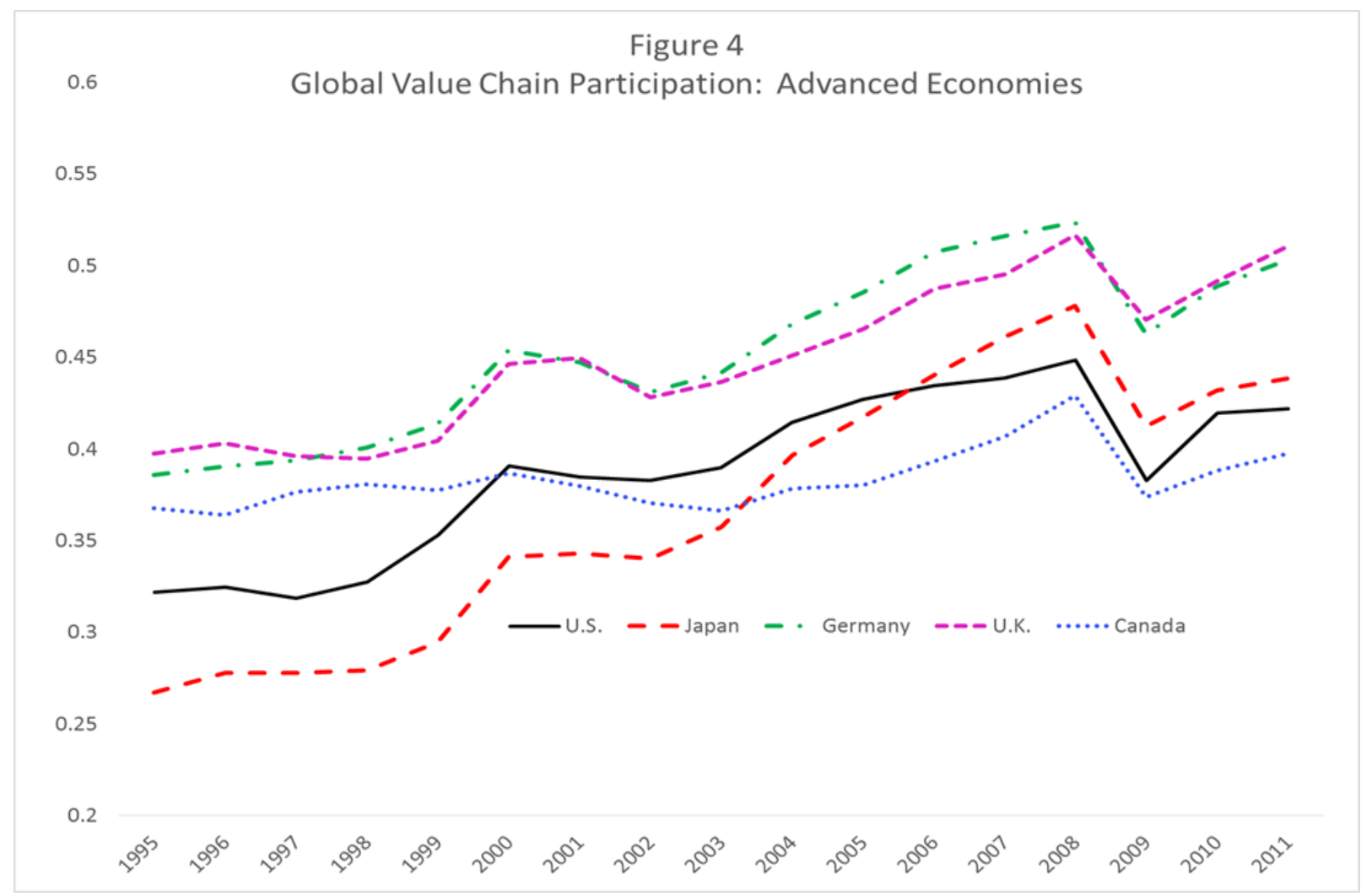




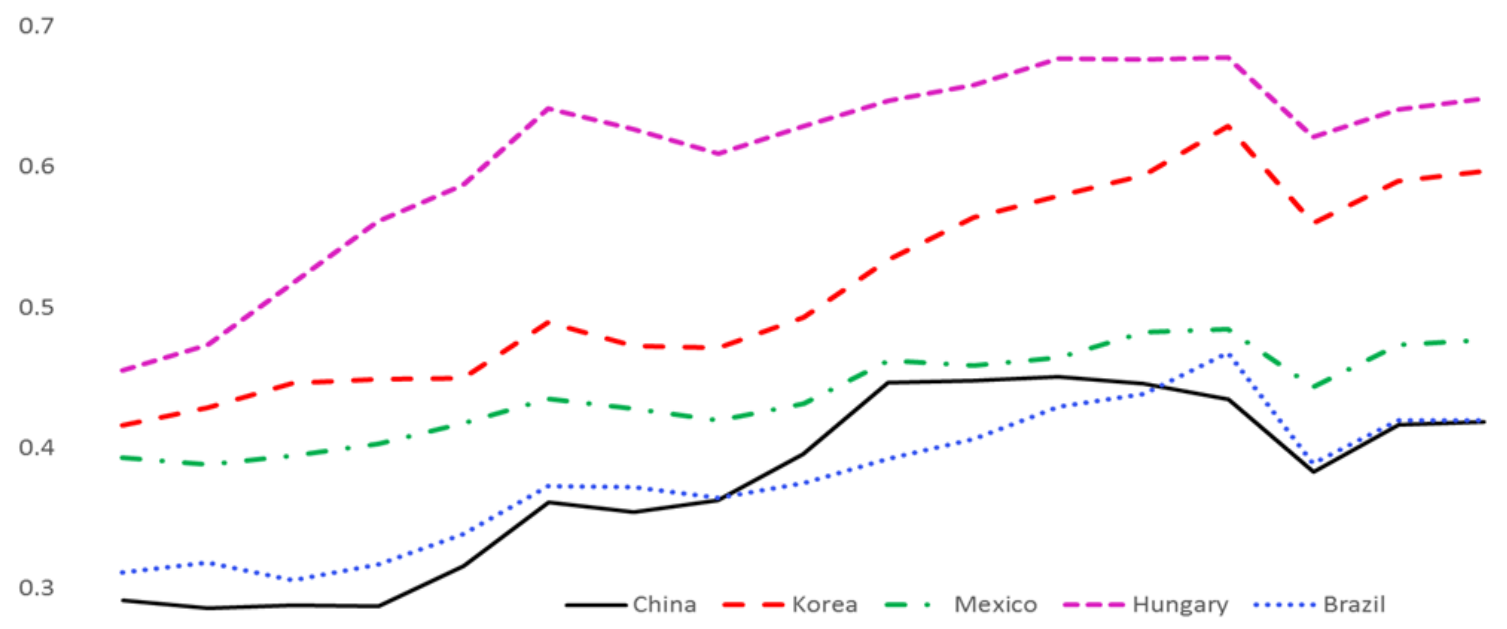

0.2

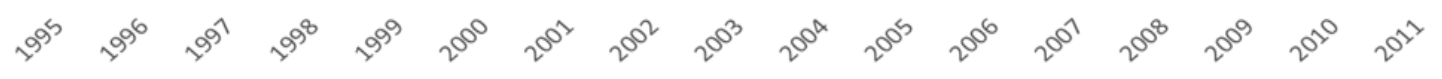

Figures 6 and 7 show the GVC position measures for the same groups of countries. The United States and Japan are the most upstream of the advanced economies, although the United Kingdom and Canada have been moving further upstream over time. In contrast, Germany has been moving downstream, with its position measure turning from positive to negative by the end of the sample. The emerging market economies as a group are further downstream, as might be expected, with their position measures mostly negative. 
Figure 6

0.2

Global Value Chain Position: Advanced Economies
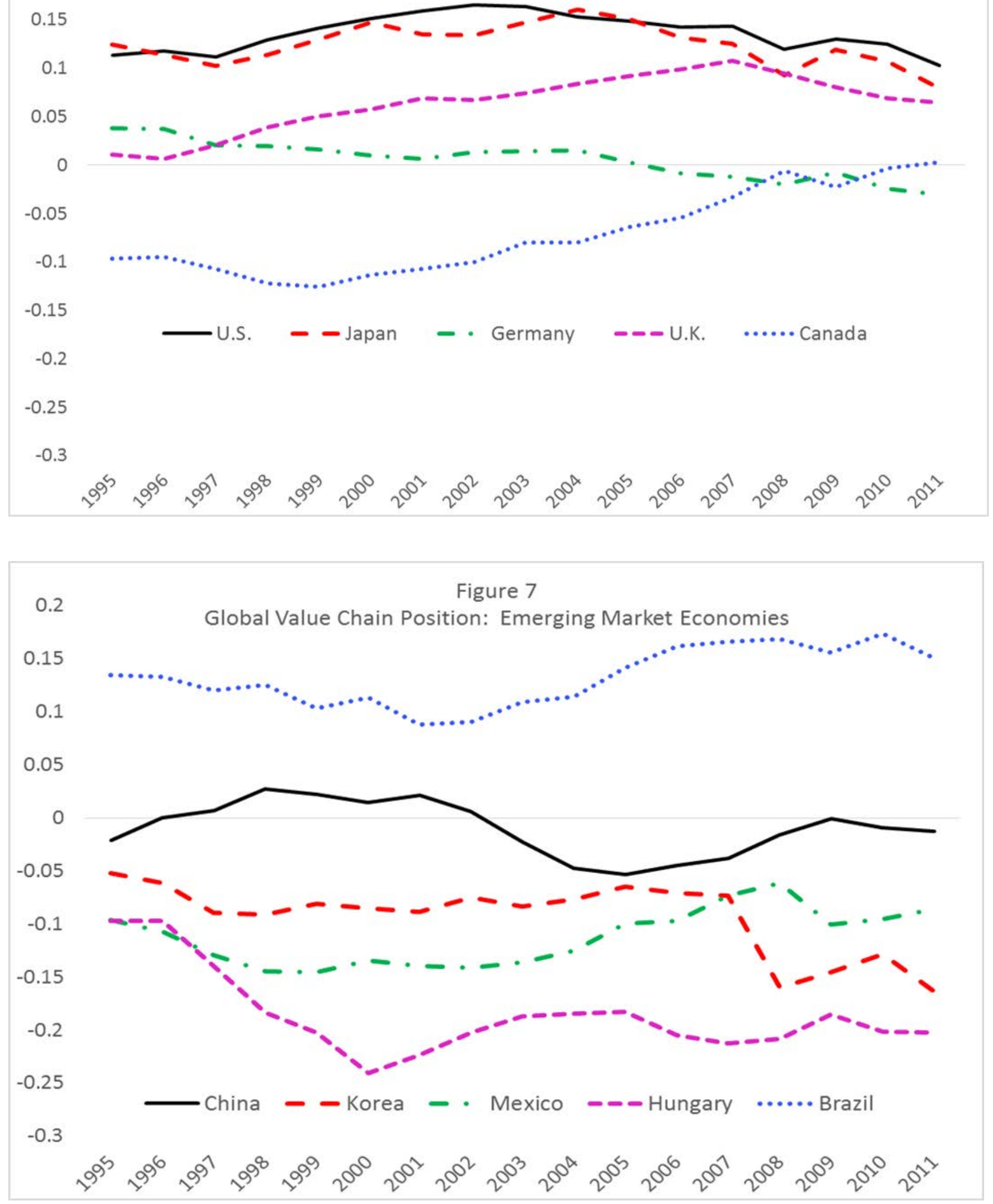
Figure 8 shows scatter plots of the participation data relative to current account balances in 1995, the beginning of the sample, and 2006, just before the onset of the Great Financial Crisis. Several developments are noteworthy. First, the overall increase in participation is quite pervasive, as evidenced by the rightward shift from values between .25 and .65 in 1995 to values between .40 and .75 in 2006. Second, current account balances are considerably more dispersed in the later period, consistent with a rise in global imbalances. Third, there does not appear to be much relationship between the extent of a country's participation in GVCs and its current account balance, as indicated by the dotted trend lines. This is perhaps not surprising given (as noted earlier) that a participating country must have a partner or partners, and if some have surpluses others will by definition have deficits.

Figure 9 shows similar graphs for global value chain position. Again, there is not much evidence of a relationship between a country’s position in a GVC and its current account balance in 1995 and only a slight positive association in 2006. The latter runs somewhat counter to the intuition that countries that are further downstream should have larger current account balances, a topic which will be discussed further below.

Of course, there are many other factors that affect current account balances, and simple graphs like these may not be able to capture the relationship. The next section uses panel regressions to assess more formally whether there is a connection between global value chains and global imbalances. 
Figure 8: Global Value Chain Participation and Current Account Balances
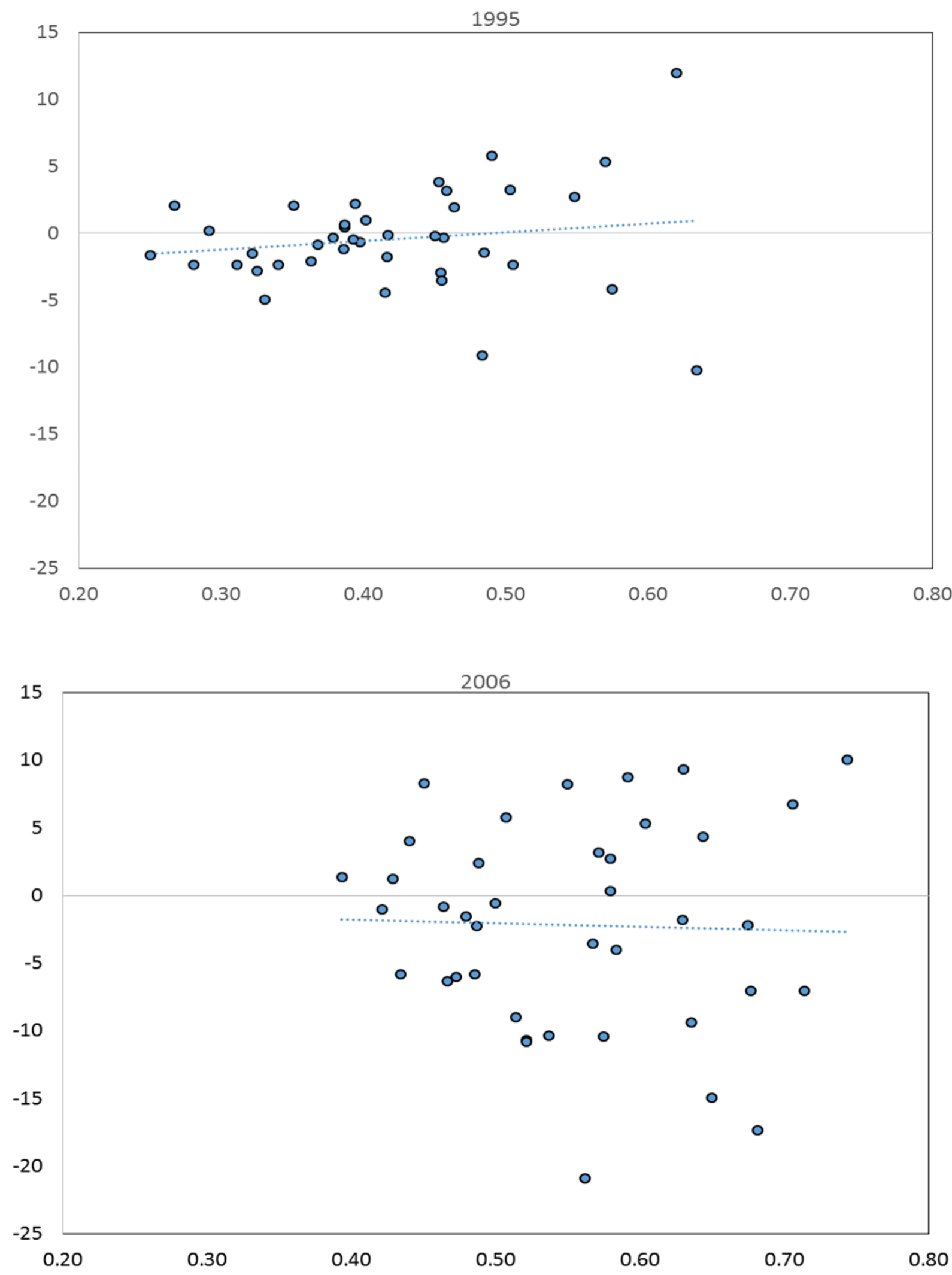
Figure 9: Global Value Chain Position and Current Account Balances
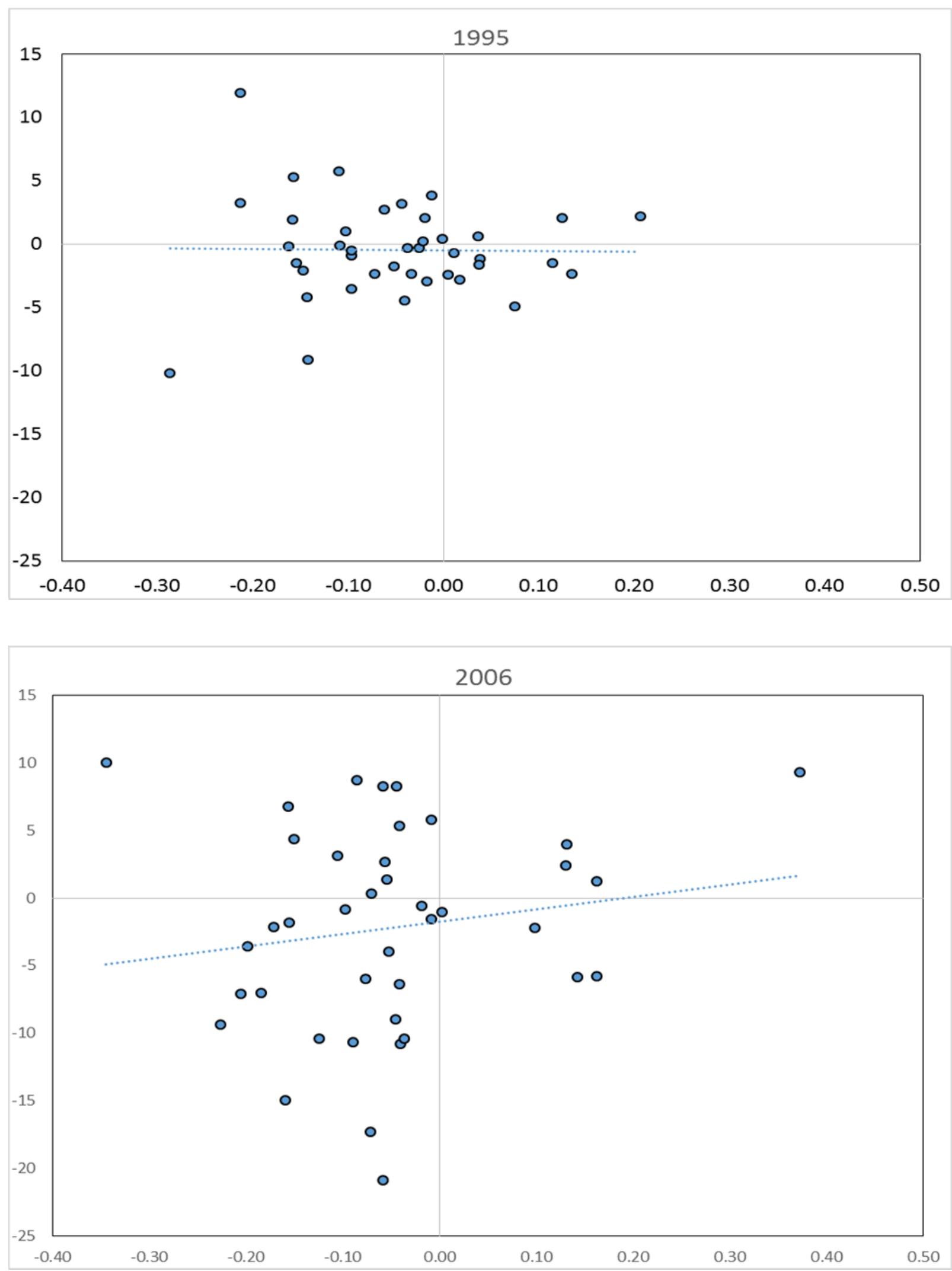


\section{Empirical Results}

As the scatter plots shown in the previous section suggest, there is no obvious simple relationship between participation in value chains and current account balances and at most a weak positive association between a country’s position in the chain and its current account balance. The latter result contradicts the speculation that current account balances of downstream countries are likely to benefit more from value chain participation than countries that are further upstream, as their function involves adding value to imports, and they are also likely to be less vulnerable to exchange rate appreciation.

GGT find a positive association between value chain participation and current account balances using the WIOD tables as well as imputed data for some other countries. ${ }^{4}$ However, as noted earlier, there is a logical fallacy in postulating a linear relationship between value chain participation and current account balances since current account surpluses in some countries necessarily have to be offset by current account deficits in others. This is not to say that such an effect might not be observed in the data. However, we need to be careful in interpreting it.

GGT also find a positive contemporaneous association between GVC position and current account balances, both when position is entered alone and when it is interacted with participation. GGT argue that this suggests that the positive effect on the current account balance comes through the value added channel, i.e. that countries that are further upstream have more of their own value-added embodied in their exports and that this should translate into a more positive current account balance. However, this does not necessarily follow. It is not the amount of value added embodied in a country’s exports that should matter for the current

\footnotetext{
${ }^{4}$ GGT measure value chain participation relative to the economy’s value added rather than to its exports.
} 
account, it is the difference between gross exports and imports. A country that is upstream in the value chain may be exporting intermediate products with a high value-added content to its value chain partners, but its imports may be entirely unrelated products that are primarily for domestic use, with no particular implications for its current account balance. On the other hand, a downstream country with a large share of GVC trade may be adding little value to each unit but still see a sizable difference between its imports and exports in aggregate.

Another important issue is that the KPWW measure of position is likely to be arithmetically contemporaneously correlated with a country’s current account balance, as it is calculated as the difference between the portion of a country's exports that add value to exports of other countries and the portion of its imports that consist of foreign value added to its exports. As these are each a subset of the country's total exports and imports, respectively, a positive difference between the two automatically translates into a higher current account balance unless offset by other components. For this reason as well as because of the time duration involved in value chain production, it may be more reasonable to assess the relationship between lagged values of position and participation and the current account balance.

As this suggests, uncovering the relationship (if any) between GVCs and current account balances is likely to require more analysis than just putting them on opposite sides of a regression. Nevertheless, this analysis starts there. Because of the relatively limited dataset, the regressions are estimated in change form so as to limit the number of control variables needed, since many of the longer-term determinants of current account balances change only slowly over time. The dependent variable is the annual change in the current account balance as a percent of GDP. 
There are two control variables: the first is the difference between the growth rate of trading-partner and domestic GDP for each country, which should be related to the demanddriven difference between growth of exports and imports. The second is the real effective exchange rate (REER) for each country. The inclusion of the latter variable cuts the crosscountry dimension of the sample to 36 from 40 , as REERs are not available for four of the countries in the WIOD dataset. However, very similar results are obtained using the larger sample without the exchange rate. Both the GDP and the exchange rate variables are multiplied by that country's share of trade in GDP since the effect of changes in trade on the current account balance relative to GDP will be larger the larger the trade share. All regressions also include country fixed effects.

The results of the equation with only the control variables are shown in table 1 along with regressions that include only the contemporaneous values of GVC position and participation, as well as one that interacts the two variables. These variables also are weighted by trade share. (When the variables are entered unweighted the signs and significance levels of the coefficients are essentially the same.)

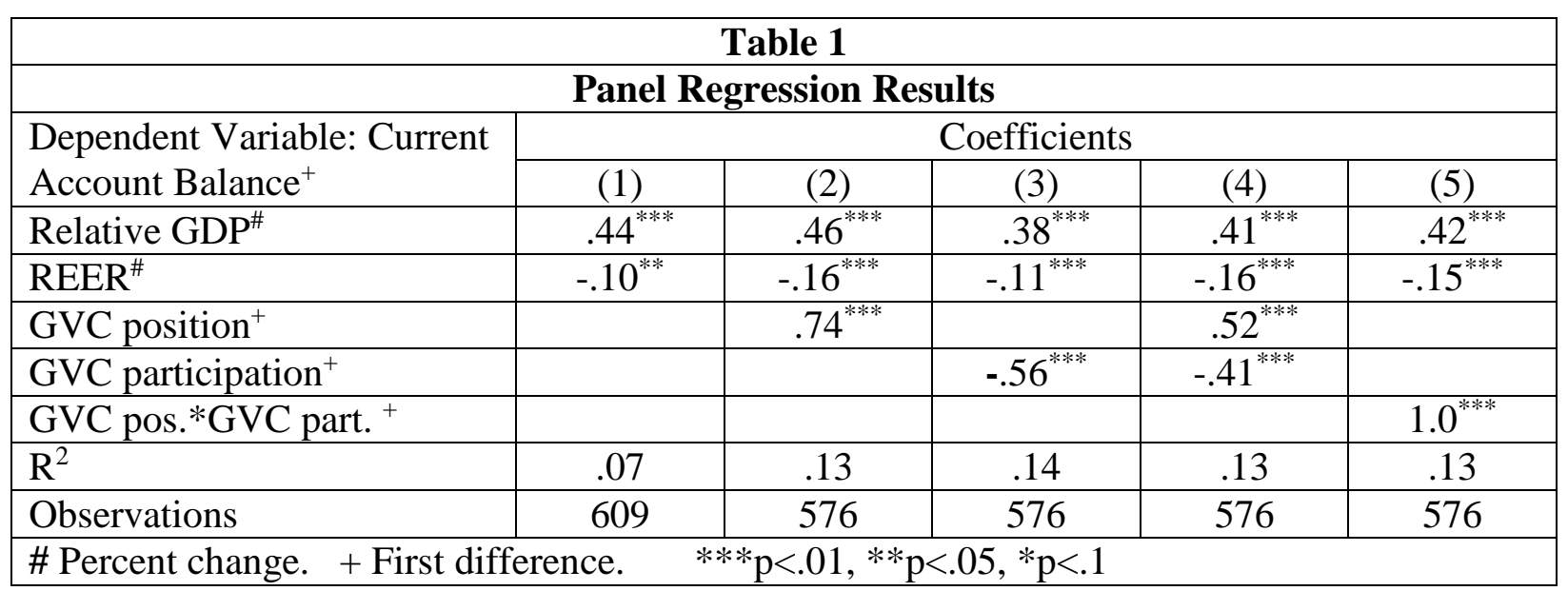


The coefficients for relative GDP growth and the real effective exchange rate are correctly signed (the GDP growth differential is positive and exchange rate appreciation is negative) and reasonably sized, and vary little as other variables are added. When entered either alone or together, contemporaneous position and participation are both highly significant, with the position variable positive (suggesting, as in the GGT results, that being upstream in the value chain is positive for current account balances). However, the negative coefficient on the participation variable suggests that value chain participation reduces current account balances. The coefficient is positive when position and participation are interacted.

However, as noted above, the contemporaneous relationship between changes in position and changes in the current account balance may be reflecting the arithmetic effect of changes in exports and imports on the current account. Furthermore, it simply cannot be the case that participation can have a negative effect for all countries even if that effect dominates across the entire sample. Some evidence that these relationships are more complicated is provided by examining the cross correlograms, shown in Figures 10-12.

The correlogram between changes in GVC position and current account balances (Figure 10) indicates that the contemporaneous positive relationship is followed by three quarters that each show an equally large negative relationship. By the fourth lagged quarter the relationship appears to disappear. The relationship between participation and current account balances (Figure 11) appears to be more persistently negative. However, when the two variables are interacted (Figure 12), the results are similar to those obtained for position. 
Figure 10: Correlogram of Changes in GVC Position and Current Account Balances

0

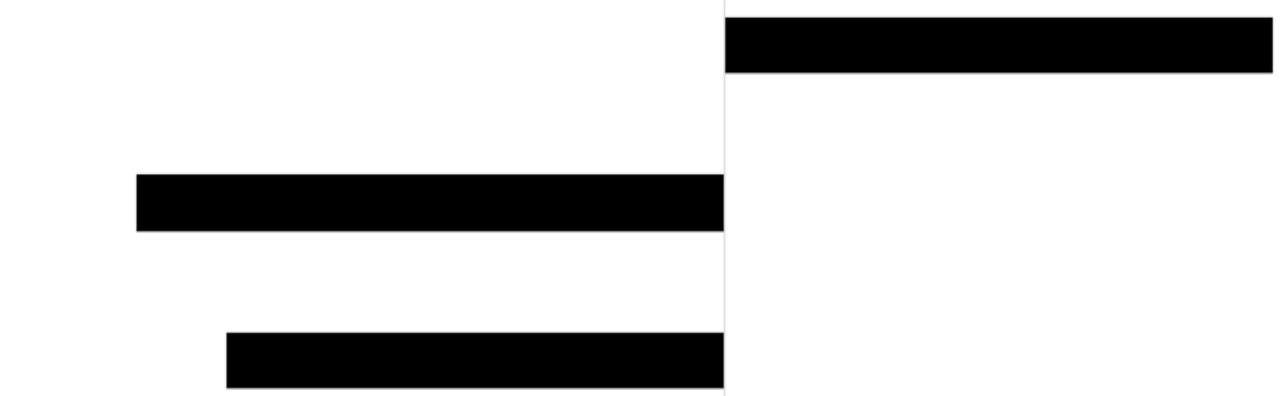

2

1

3

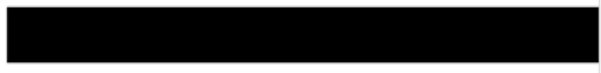

4

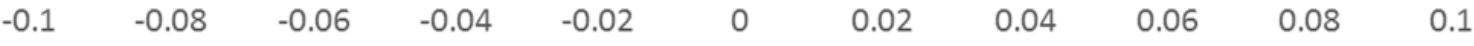

Figure 11: Correlogram of Changes in GVC Participation and Current Account Balances

0

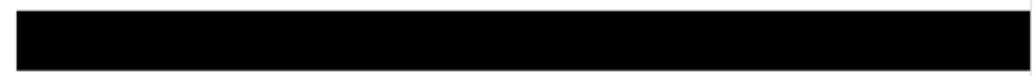

1

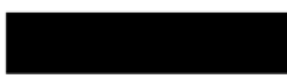

2

3

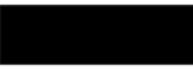

4

0 


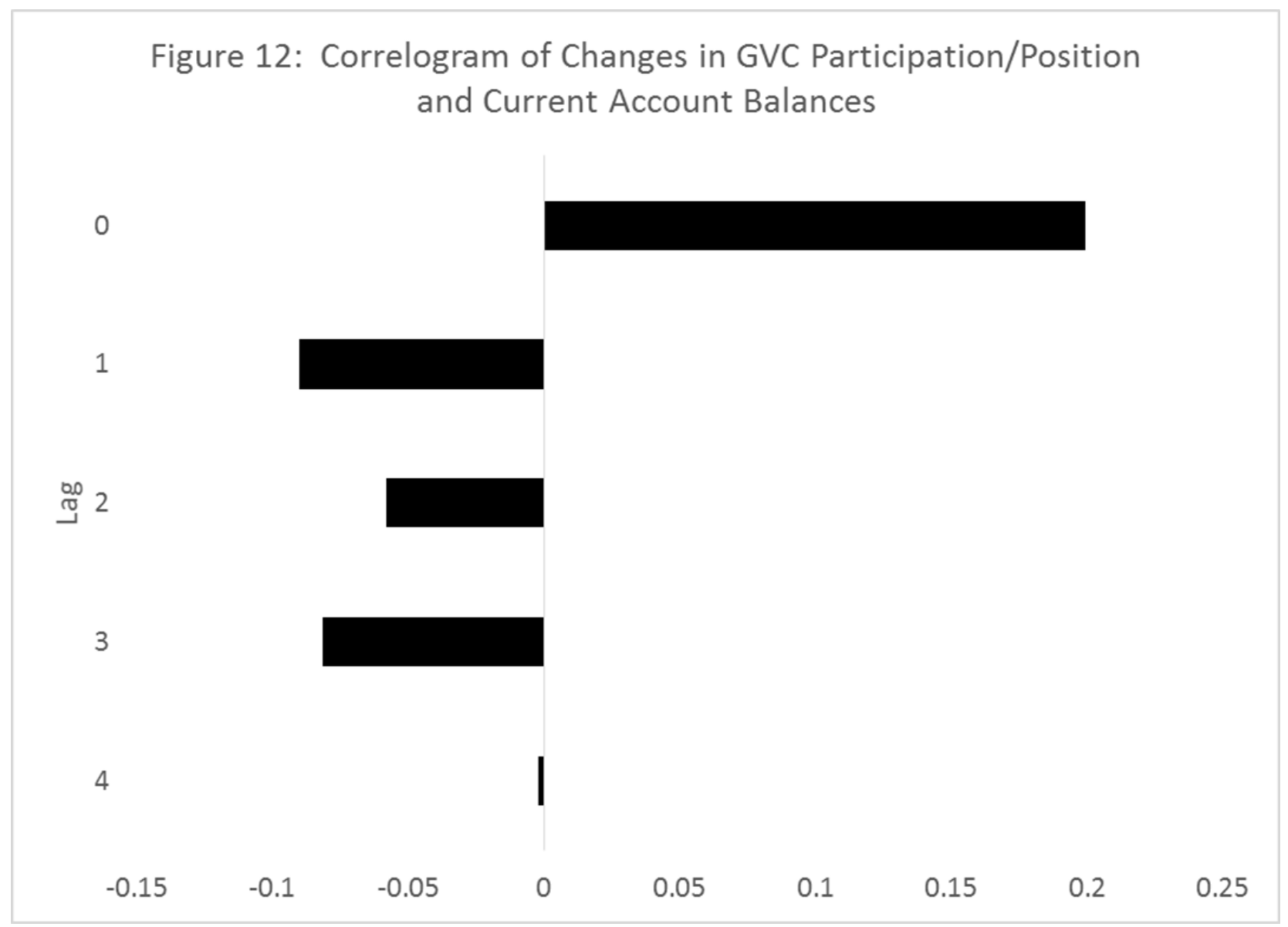

An argument can be made that interacting the variables makes the most sense from an economic point of view when assessing the relationship with the current account balance. If a country's position in the value chain affects its current account balance, the relationship will almost certainly be stronger for a country that has a high level of participation than for one that has a low level.

Table 2 shows the results from two regressions that include the position and participation terms interacted, the first including the contemporaneous term and the second starting with the first lag. The results are quite different. If the contemporaneous term is included, the sum of the lags is positive but only the current and third lags are significant. If the current term is excluded, the relationship is negative and significant for the first, second, and third lags. Overall, this 
result suggests that abstracting from the direct arithmetic effect of GVC position on current accounts, an increase in "upstreamness” reduces the current account balance and an increase in downstreamness increases it, with the full effect coming after three years.

\begin{tabular}{|c|c|c|}
\hline \multicolumn{3}{|c|}{ Table 2} \\
\hline \multicolumn{3}{|c|}{ Panel Regression Results } \\
\hline $\begin{array}{l}\text { Dependent Variable: Current } \\
\text { Account Balance }^{+}\end{array}$ & \multicolumn{2}{|c|}{ Coefficients } \\
\hline Relative GDP ${ }^{\#}$ & $.33^{* * *}$ & $.41^{* * *}$ \\
\hline $\mathrm{REER}^{\#}$ & $-.15^{* * *}$ & $-.11^{* *}$ \\
\hline GVC pos. ${ }^{*}$ GVC part. ${ }^{+} \mathrm{L}=0$ & $.52^{* * *}$ & \\
\hline GVC pos. ${ }^{*}$ GVC part. ${ }^{+} \mathrm{L}=1$ & .03 & -.05 \\
\hline GVC pos. ${ }^{*}$ GVC part. ${ }^{+} \mathrm{L}=2$ & $-.22^{* *}$ & $-.30^{* * *}$ \\
\hline GVC pos. ${ }^{*}$ GVC part. ${ }^{+} \mathrm{L}=3$ & -.14 & $-.29^{* *}$ \\
\hline $\mathrm{R}^{2}$ & .12 & .08 \\
\hline Observations & 468 & 468 \\
\hline
\end{tabular}

However, the importance of this effect for a country’s current account balance will depend on the size of the changes in GVC position. A sense of how important this effect is likely to be can be obtained by looking at the sample averages. The average participation index over all countries and all time periods is about .5 and the average trade share is about .44 . At these averages, a change in GVC position of .015 (the average of the changes in the sample) would raise or lower a country’s current account balance by just 0.2 percentage points. Of course, the changes might be larger for some countries.

The first two columns of Table 3 show the amount that each country's change in GVC position is estimated to have contributed to the change in its current account balance both before the crisis, (1999-2006) as well as since (2007-2011) using the coefficients in the second column of table 2 along with the actual data for each country. The changes are positive for some countries and negative for others. The last three rows show aggregate measures: first the simple 
sum of the changes, then the sum of the absolute value of the changes, which is more relevant for global imbalances, then the absolute value as a percent of global GDP.

These results suggest that participation in GVCs has overall made a negative contribution to current account balances in both periods, about $\$ 24$ billion in the first period and $\$ 19$ billion in the second. In the first period, the United States showed the largest increase in its deficit as a result of growing involvement in GVCs, $-\$ 21$ billion, although this decline is partly reversed in the later period. For the individual countries, China showed the largest increase in its surplus in the first period, although it also showed a substantial drop in the second period as it apparently moved more upstream. The rest of the world aggregate also showed a gain. The sum of the absolute value of the changes is about 4 percent of global GDP in each period, compared with an increase in the aggregate measure of global imbalances from 1.8 percent to 4.6 percent of global GDP between 1995 and 2006.

However, while this measure is an estimate of the change that might result in global imbalances from the rise of GVCs in a world in which all countries started with a balanced current account, this is obviously not the starting point in the real world, where the effect on global imbalances of a given change in an individual country's current account balance will depend on whether the country started with a surplus or deficit. That is, reductions in deficits for deficit countries or surpluses in surplus countries will contribute to a reduction in global imbalances, while the opposite is true if either deficits or surpluses increase in absolute value. The third and fourth columns show the effect of the changes on global imbalances by multiplying the change by -1 if the country had a deficit at the beginning of each period and by 1 if the country had a surplus. Thus, a positive effect of GVC participation will reduce the global imbalance if the country has a deficit and increase it if it has a surplus, and vice versa. 


\begin{tabular}{|c|c|c|c|c|}
\hline \multicolumn{5}{|c|}{ Table 3: Estimated Effect of GVCs on Current Account Balance (Billions of US\$) } \\
\hline & \multicolumn{2}{|c|}{ No Adj. for Previous Balance } & \multicolumn{2}{|c|}{ Adj. for Previous Balance } \\
\hline & $1999-2006$ & $2007-2011$ & $1999-2006$ & $2007-2011$ \\
\hline Australia & -2.0 & -3.9 & 2.0 & 3.9 \\
\hline Austria & 1.3 & 1.1 & -1.3 & 1.1 \\
\hline Belgium & -0.9 & 6.2 & -0.9 & 6.2 \\
\hline Bulgaria & 0.0 & 0.4 & 0.0 & -0.4 \\
\hline Brazil & -2.4 & -3.4 & 2.4 & -3.4 \\
\hline Canada & -3.0 & -8.9 & 3.0 & -8.9 \\
\hline China & 8.5 & -19.4 & 8.5 & -19.4 \\
\hline Cyprus & -0.1 & 0.0 & -0.1 & 0.0 \\
\hline Czech Rep. & 2.7 & 1.9 & -2.7 & -1.9 \\
\hline Germany & 1.2 & 12.1 & -1.2 & 12.1 \\
\hline Denmark & -0.1 & 5.0 & 0.1 & 5.0 \\
\hline Spain & -0.3 & 1.5 & 0.3 & -1.5 \\
\hline Estonia & -0.1 & -0.4 & 0.1 & 0.4 \\
\hline Finland & -0.7 & 2.7 & -0.7 & 2.7 \\
\hline France & -0.3 & 4.9 & -0.3 & -4.9 \\
\hline United Kingdom & -9.6 & -5.5 & 9.6 & 5.5 \\
\hline Greece & -0.2 & -0.6 & 0.2 & 0.6 \\
\hline Hungary & 1.4 & 2.2 & -1.4 & -2.2 \\
\hline Indonesia & -1.7 & -1.5 & -1.7 & -1.5 \\
\hline India & -0.8 & 4.8 & 0.8 & -4.8 \\
\hline Ireland & 0.1 & 1.7 & 0.1 & -1.7 \\
\hline Italy & -2.2 & 5.0 & -2.2 & -5.0 \\
\hline Japan & -10.8 & 1.4 & -10.8 & 1.4 \\
\hline Korea & 3.1 & 22.8 & 3.1 & 22.8 \\
\hline Lithuania & -0.1 & 0.5 & 0.1 & -0.5 \\
\hline Luxembourg & 2.2 & 3.6 & 2.2 & 3.6 \\
\hline Latvia & 0.0 & -0.1 & 0.0 & 0.1 \\
\hline Mexico & 1.6 & -2.6 & -1.6 & 2.6 \\
\hline Malta & -0.2 & -0.1 & 0.2 & 0.1 \\
\hline Netherlands & -3.1 & 5.9 & -3.1 & 5.9 \\
\hline Poland & 1.8 & 0.8 & -1.8 & -0.8 \\
\hline Portugal & -0.1 & 0.0 & 0.1 & 0.0 \\
\hline Romania & 0.3 & -1.4 & -0.3 & 1.4 \\
\hline Russia & -6.9 & -11.4 & -6.9 & -11.4 \\
\hline Slovak Rep. & 1.2 & -1.1 & -1.2 & 1.1 \\
\hline Slovenia & 0.2 & 0.1 & -0.2 & -0.1 \\
\hline Sweden & 0.0 & 2.8 & 0.0 & 2.8 \\
\hline Turkey & 1.3 & -4.5 & 1.3 & 4.5 \\
\hline Taiwan & 4.3 & 6.5 & 4.3 & 6.5 \\
\hline United States & -20.5 & 4.9 & 20.5 & -4.9 \\
\hline Rest of World & 14.8 & -52.4 & 14.8 & -52.4 \\
\hline Sum & -20.3 & -18.7 & 35.3 & -35.4 \\
\hline Sum of Abs.Val. & 112.0 & 215.6 & & \\
\hline Abs. Val. \% GDP & .36 & .37 & .07 & .04 \\
\hline
\end{tabular}


These calculations suggest that GVCs have had a very small effect on global imbalances in both periods. The biggest contributors to this result are Japan, Russia, and the Netherlands, all of which had a surplus at the beginning of each period that was reduced by a negative effect from the change in its GVC participation/position. In the later period, the largest contributor to the reduction in global imbalances from GVC participation/position was China. In contrast, both Korea and Germany experienced changes in GVC participation/position that contributed to a widening of global imbalances, although these amounts are still small relative to global GDP.

To sum up, the evidence suggests that a country's position in GVCs, weighted by participation and trade share, can have a significant effect on its current account balance after several years, with countries that move upstream seeing downward pressure on their balances and vice versa. However, using the coefficients estimated here, the effects over the sample period have been small.

\section{Conclusion}

Two phenomena that have characterized the years since the mid-1990s have been a sharp increase in both global imbalances and global value chains, particularly in the pre-crisis period. This raises the question of whether the rise in value chains has contributed to the increase in imbalances. This paper calculates the measures of value chain position and participation using the methodology developed by KPWW and uses them to try to answer this question.

Regressions that look at the relationship of these variables contemporaneously suggest that increased participation in global value chains has a negative effect on a country's current account balance (contrary to GGT's result), while moving upstream in production has a positive effect. However, entering GVC participation by itself into a panel regression is problematic, as it 
suggests that all countries will see either a reduction or an increase in their current account balances, but if participation is widespread, these changes will need to be offsetting. The position variable suffers from a different limitation, as it is contemporaneously correlated in an arithmetic sense with a country's trade balance and thus its current account. This paper has attempted to address these issues by interacting the two variables and lagging them. The results suggest that changes in GVC position are significantly negatively related to changes in a country's current account balance, but the magnitude of the coefficients indicates that the effect on global imbalances over the sample period has been small.

\section{References}

Amador, Joao and Sonia Cabral, “Global Value Chains: Surveying Drivers and Measures,” ECB Working Paper 1739, 2014.

Antras, Po and Davin Chor, “Organizing the Global Value Chain,” NBER Working Paper 18163, 2012.

Bems, Rudolfs, and Robert Johnson, "Value-Added Exchange Rates,” NBER Working Paper 18498, 2012.

Chen, Hogan, Matthew Kondratowicz, and Kei-Mu Yi, "Vertical Specialization and Three Facts about U.S. International Trade,” North American Journal of Economics and Finance, 16: 35-39, 2005.

Daudin, Guillaume, Christine Rifflart, and Danielle Schweisguth, "Who Produces for Whom in the World Economy?” Canadian Journal of Economics, 2011.

Dietzenbacher, E., B. Los, R. Stehrer, M.P. Timmer and G.J de Vries, “The Construction of World Input-Output Tables in the WIOD Project,” Economic Systems Research, 25, 71-98, 2013.

Fally, Thibault, “On the Fragmentation of Production in the US,” 2011.

Feenstra, R.C., and G.H. Hanson, “Globalization, Outsourcing, and Wage Inequality,” American Economic Review 86(20), 240-45, 1996.

Georgiadis, Georgios, Johannes Grab, and Fabian Trottner, "Global Chain Participation and Current Account Imbalances,” December 2014. 
Hummels, David, Jun Ishii, and Kei-Mu Yi, “The Nature and Growth of Vertical Specialization in World Trade,” Journal of International Economics, Vol. 54(1), 2001.

IMF, “Trade Interconnectedness: The World With Global Value Chains,” 2013.

Johnson, Robert, "Five Facts about Value-Added Exports and Implications for Macroeconomics and Trade Research,” Journal of Economic Perspectives, 2014.

Johnson, Robert, and Guillermo Noguera, "Fragmentation and Trade in Value Added Over Four Decades,” NBER Working Paper 18186, 2012.

Johnson, Robert, and Guillermo Noguera, “Accounting for Intermediates: Production Sharing and Trade in Value Added,” Journal of International Economics, 2011.

Koopman, Robert, William Powers, Zhi Wang, and Shang-Jin Wei, “Give Credit Where Credit is Due: Tracing Value Added in Global Production Chains,” NBER Working paper 16426, 2010.

Koopman, Robert, Zhi Wang, and Shang-Jin Wei, "How Much of Chinese Exports is Really Made in China? Assessing Domestic Value-Added When Processing Trade is Pervasive,” NBER Working paper 14109, 2008.

Lejour, Arjan, Hugo Rojas-Romagosa and Paul Veenendall, "Identifying Hubs and Spokes in Global Supply Chains Using Redirected Trade in Value Added,” ECB Working Paper 1670, 2014.

Matras, Chor, D., Fally, T., and Hillberry, H., "Measuring the Upstreamness of Production and Trade Flows,” NBER Working Paper 17819, February 2012

Riad, Nagwa, Luca Errico, Christian Henn, Christian Saborowski, Mika, and Jarkko, Turunen, “Changing Patterns of Global Trade,” IMF, 2012.

Timmer, M. P., Erumban, A., Los, B., Stehrer, R., and de Vries, G., Slicing Up Global Value Chains,” Journal of Economic Perspectives 28(2), 99-118, 2014.

Timmer, M. P., Dietzenbacher, E., Los, B., Stehrer, R., and de Vries, G.J., “An Illustrated Guide to the World Input-Output Database: The Case of Global Automotive Production,” Review of International Economics, 23: 575-605, 2015.

\section{Appendix: Data Sources}

As noted above, the global value chain measures were calculated using the World Input-

Output database. The current account and GDP data are from the IMF's World Economic

Outlook. Trade-weighted trading partner GDP is calculated for each country using export weights from the IMF's Direction of Trade Statistics. The real effective exchange rates are from the IMF's International Financial Statistics database. 